\title{
Relação entre distribuição de nitrogênio e colonização por bactérias diazotróficas em cana-de-açúcar
}

\author{
Arão Araújo Gomes ${ }^{(1)}$, Veronica Massena Reis(2), Vera Lucia Divan Baldani( ${ }^{(2)}$ e Silvia Regina Goi(3)
}

\begin{abstract}
(1)Escola Agrotécnica Federal de São Cristóvão, Rod. BR 101, Km 96, Povoado Quisamã, CEP 49100-000 São Cristovão, SE. E-mail: haaron@bol.com.br (2)Embrapa Agrobiologia, BR 465, Km 47, CEP 23890-000 Seropédica, RJ. E-mail: vera@cnpab.embrapa.br, veronica@cnpab.embrapa.br (3)Universidade Federal Rural do Rio de Janeiro, Instituto de Florestas, BR 465, Km 47, CEP 23890-000 Seropédica, RJ. E-mail: sgoi@ufrrj.br
\end{abstract}

\begin{abstract}
Resumo - O objetivo deste trabalho foi avaliar a relação entre a distribuição de nitrogênio na planta e a colonização por Gluconacetobacter diazotrophicus e Herbaspirillum spp. Foi implantado um experimento em parcelas subdivididas, tendo como tratamentos quatro genótipos: SP70-1143, SP79-2312 (híbridos), Krakatau (Saccharum spontaneum L.) e Chunnee (Saccharum barberi Jesw.); e quatro épocas de coleta: 90, 180, 360 e 540 dias após o plantio, com quatro repetições. Os parâmetros estudados foram: porcentual de nitrogênio, nitrato, $\mathrm{N}$ amino livre e o número mais provável de população das bactérias Gluconacetobacter diazotrophicus e Herbaspirillum spp. Os valores mais elevados de nitrogênio foram observados aos 90 dias após o plantio, nas folhas e colmo apical; as maiores concentrações $\mathrm{N}$ amino ocorreram nas raízes, colmo basal e folhas da variedade SP79-2312 e no colmo apical do genótipo Chunnee. O maior acúmulo de nitrato foi observado nos colmos basais e intermediários, sobretudo na variedade SP79-2312. O N protéico mostrou ser o maior componente do nitrogênio porcentual, com a mesma tendência nas diferentes partes da planta. O maior valor na população de G. diazotrophicus ocorreu nas raízes de SP70-1143, SP79-2312 e Krakatau, e nos quatro genótipos de Herbaspirillum spp.
\end{abstract}

Termos para indexação: cana-de-açúcar, nutrição de plantas, bactérias endofíticas.

\section{Relationship between nitrogen distribution and diazotrophic bacteria colonization in sugarcane}

\begin{abstract}
The objective of this work was to evaluate the relation between nitrogen distribution in plants of sugarcane, and the colonization by Gluconacetobacter diazotrophicus and Herbaspirillum spp. The experimental design was a split plot, with four genotypes of sugarcane: SP70-1143 and SP79-2312 (hybrids), Krakatau (Saccharum spontaneum L.) and Chunnee (Saccharum barberi Jesw.), and four times of harvest: 90, 180, 360, 540 days after planting, and four replications. The parameters evaluated were: nitrogen percentage, nitrate, free amino-N, and the most probable number of Gluconacetobacter diazotrophicus and Herbaspirillum spp. population. The percentage of nitrogen showed higher values at 90 days after planting in leaves and apical stems, and the largest concentrations of amino-N occurred in the roots, basal stems, and leaves of SP79-2312 variety and in apical stems of the Chunnee genotype. The largest nitrate accumulation was observed in the basal and intermediary stems, mainly in SP79-2312 variety. Proteic-N was the main component of the total nitrogen content, with the same tendency in different parts of the plant. Highest value of G. diazotrophicus population occured in the roots of SP70-1143, SP79-2312, Krakatau and in the four genotypes of Herbaspirillum spp.
\end{abstract}

Index terms: sugarcane, plant nutrition, endophytic bacteria.

\section{Introdução}

A cana-de-açúcar é uma das principais culturas agrícolas, cultivada em regiões tropicais e subtropicais do globo terrestre. A maioria das variedades brasileiras foi selecionada sob condições de baixa fertilidade, tendo-se minimizado a utilização dos adubos nitrogenados
(Azeredo et al., 1986), e constituiu-se em vantagem para se estudar o processo de fixação biológica de nitrogênio (FBN). Em estudos de quantificação da FBN, pela associação de bactérias diazotróficas endofíticas com a planta, foi verificado que na variedade CB 47-89 ocorreu um acúmulo equivalente a mais de $150 \mathrm{~kg} \mathrm{ha}^{-1}$ de N, e em CB 45-3 e SP70-1143 uma contribuição de 170 a 
$210 \mathrm{~kg} \mathrm{ha}^{-1}$ de $\mathrm{N}$, com valores entre $60 \%$ e $70 \%$ de nitrogênio incorporado à planta, derivado do processo da FBN (Urquiaga et al., 1992). Entretanto, a contribuição da FBN é muito diferente entre as variedades (Yoneyama et al., 1997).

O nitrogênio é constituinte obrigatório de aminoácidos, proteínas e ácidos nucléicos, participa direta e indiretamente de diversos processos bioquímicos das plantas, e pode ser encontrado também na forma inorgânica $\left(\mathrm{NO}_{3}{ }^{-}\right.$e $\left.\mathrm{NH}_{4}{ }^{+}\right)$. O nitrato é prontamente absorvido e convertido por enzimas e, em contato com carboidratos, forma as amidas e aminoácidos, passando então da forma inorgânica para a orgânica (Fernandes \& Rossiello, 1995). E um dos nutrientes mais extraídos do solo pela planta da cana, considerada de elevada eficiência fisiológica na utilização de nitrogênio (Silveira, 1985), por isso pouco responsiva à fertilização nitrogenada.

Em estudos sobre o efeito da adubação nitrogenada, Azeredo et al. (1986) verificaram que somente em 20\%, de 135 experimentos de campo conduzidos no Brasil, foram observados efeitos positivos que incrementaram a produção. A assimilação de nitrogênio é estreitamente relacionada com o metabolismo de carboidratos e provoca acentuada diminuição nos níveis de açúcares do colmo, com menor expressão na bainha (Silveira, 1985). Os valores de nitrogênio e de açúcar variam com a idade da cana, em razão inversa; na fase inicial da cultura prevalece o primeiro, enquanto o segundo é incrementado com o desenvolvimento (Clements, 1980).

A associação entre bactérias diazotróficas e a canade-açúcar envolve diversos gêneros bacterianos e mecanismos singulares ainda pouco compreendidos (James, 2000). Entre outras bactérias associadas à canade-açúcar, responsáveis pela FBN, destacam-se as espécies Gluconacetobacter diazotrophicus $e$ Herbaspirillum spp. G. diazotrophicus está inserida no grupo das bactérias do ácido acético e foi isolada de raízes e parte aérea de cana-de-açúcar por Cavalcante \& Döbereiner (1988). Já as bactérias do gênero Herbaspirillum são naturalmente associadas às gramíneas e aí se incluem as espécies $H$. seropedicae e H. rubrisubalbicans (Baldani et al., 1986, 1996).

Diversas bactérias diazotróficas são capazes de produzir fitormônios, responsáveis pelo efeito estimulatório observado no crescimento de plantas. Bastián et al. (1998) detectaram a presença de ácido indol-acético (AIA) e giberelinas $A_{1}$ e $A_{3}$, em culturas de Herbaspirillum seropedicae, e Fuentes-Ramírez et al. (1993) avaliaram a produção de AIA por estirpes de Gluconacetobacter diazotrophicus.

Embora se conheça a importância do nitrogênio para o crescimento vegetal, muito pouco foi feito sobre a dis- tribuição de suas diferentes formas, na cana-de-açúcar, e sobre como esses compostos se comportam em relação à população de bactérias diazotróficas naturalmente presentes na cultura.

O objetivo deste trabalho foi avaliar a relação entre a distribuição de nitrogênio em cana-de-açúcar e a colonização por G. diazotrophicus e Herbaspirillum spp.

\section{Material e Métodos}

O experimento foi instalado no campo Experimental da Embrapa Agrobiologia, situado no Município de Seropédica, RJ, em um Planossolo. O delineamento utilizado foi o de blocos ao acaso, com quatro repetições, em esquema de parcelas subdivididas no tempo: aos 90, 180, 365 e 540 dias após o plantio (DAP). Na parcela, foram avaliados quatro genótipos e, nas subparcelas, as épocas de coletas dos dados. Os genótipos avaliados na parcela foram escolhidos em razão do comportamento contrastante, em relação ao processo de fixação biológica de nitrogênio e de acúmulo de sacarose, sendo dois de canas cultivadas comercialmente: a SP70-1143, considerada de boa performance para fixação biológica de nitrogênio (FBN) e de ciclo tardio, e a SP79-2312, de performance inferior à primeira em relação à FBN e de ciclo precoce. Os outros genótipos foram Krakatau (Saccharum spontaneum) e Chunne (Saccharum barberi).

As variedades foram plantadas na mesma época, em parcelas onde cada cultivar representava uma subparcela, plantada em linhas espaçadas por $1 \mathrm{~m}$, com distâncias entre plantas de $50 \mathrm{~cm}$, com dois toletes e duas gemas por cova. Após a análise do solo, foi feita adubação conforme recomendado para a cultura, que consistiu na aplicação de 2 t ha ${ }^{-1}$ de calcáreo dolomítico, $100 \%$ PRNT, 60 dias antes do plantio, e as covas receberam doses de $100 \mathrm{~kg} \mathrm{ha}^{-1} \mathrm{de}_{2} \mathrm{O}$, na forma de cloreto de potássio, e $150 \mathrm{~kg} \mathrm{ha}^{-1}$ de $\mathrm{P}_{2} \mathrm{O}_{5}$, na forma de superfosfato simples. Como adubação para suprir as necessidades em micronutrientes usou-se $50 \mathrm{~kg} \mathrm{ha}^{-1}$ de FTE BR-12.

As amostras foram separadas em raízes vivas e finas, colmo basal (dois entrenós situados $5 \mathrm{~cm}$ acima do nível do solo), colmo intermédio (retirou-se amostra de dois colmos do centro do tolete), colmo apical (entrenós 1 e 2) e, finalmente, foi amostrada a folha +3, tendo-se retirado a nervura central e considerado apenas os $20 \mathrm{~cm}$ centrais. As amostras foram colhidas no campo e acomodadas em gelo, para o transporte até o laboratório, onde se procedeu à pesagem de $1 \mathrm{~g}$ de material fresco, que foi imerso em solução de etanol a $80 \%$ e estocado a $5^{\circ} \mathrm{C}$, por 15 dias. Após esse período, foi feita a partição, utilizando-se como extrator o clorofór- 
mio, determinando-se na fração polar obtida os teores de aminoácidos livres (Yemm \& Cocking, 1955) e nitrogênio nítrico (Cataldo et al., 1975). O teor de nitrogênio total foi determinado em amostras de $200 \mathrm{mg}$ de material seco e moído, por digestão sulfúrica, seguida de destilação e titulação segundo Tedesco (1983).

A contagem da população bacteriana foi realizada pelo método do número mais provável (NMP), em amostras frescas de $10 \mathrm{~g}$ das partes analisadas da planta, trituradas em $90 \mathrm{~mL}$ de solução salina à base de $3 / 4$ de sais do meio NFb. As células viáveis foram estimadas a partir do crescimento de película nas diluições seriadas e foram inoculadas em meio de cultura semi-sólido LGI-P caldo (semi-específico para a contagem de Gluconacetobacter diazotrophicus) e JNFb (semiespecífico para a contagem de Herbaspirillum spp.), sem nitrogênio descritos por Döbereiner et al. (1995). A determinação do número de células baseou-se na presença ou ausência de película, característica da espécie, em frasco com capacidade de $10 \mathrm{~mL}$, utilizandose a tabela de McCrady.

Os testes estatísticos (análise de variância, teste de médias e correlações) foram feitos com a utilização do programa MSTAT-C (Michigan State University, 1989). As médias foram comparadas utilizando-se o teste de Tuckey a 5\% de probabilidade.

\section{Resultados e Discussão}

O porcentual de nitrogênio nas raízes atingiu o valor máximo aos $360 \mathrm{DAP}$, tendo chegado à média de $0,7 \%$ (Tabela 1). Clements (1980) refere-se à fase de crescimento inicial em que as raízes são ativas e contêm consideráveis quantidades de nitrogênio e que, com a idade da cultura, há o declínio da atividade radicular, acompanhado por decréscimo do nitrogênio.

Tabela 1. Nitrogênio total (valor porcentual), em diferentes partes da planta de cana-de-açúcar (Saccharum spp.), em função de dias após plantio (DAP) ${ }^{(1)}$.

\begin{tabular}{|c|c|c|c|c|c|}
\hline DAP & SP70-1143 & SP79-2312 & Krakatau & Chunnee & Média \\
\hline & & & Raízes & & \\
\hline 90 & $0,474 a b$ & $0,527 \mathrm{a}$ & $0,485 \mathrm{ab}$ & $0,404 b$ & $0,472 \mathrm{D}$ \\
\hline 180 & $0,582 \mathrm{ab}$ & $0,718 \mathrm{a}$ & $0,646 a$ & $0,468 b$ & $0,604 \mathrm{~B}$ \\
\hline 360 & $0,700 \mathrm{a}$ & $0,660 \mathrm{a}$ & $0,709 \mathrm{a}$ & $0,735 a$ & $0,701 \mathrm{~A}$ \\
\hline 540 & $0,617 \mathrm{a}$ & $0,612 \mathrm{a}$ & $0,548 \mathrm{a}$ & $0,439 \mathrm{~b}$ & $0,554 \mathrm{C}$ \\
\hline \multirow[t]{2}{*}{ Média } & $0,593 \mathrm{ab}$ & $0,629 a$ & $0,597 \mathrm{ab}$ & $0,511 \mathrm{c}$ & \\
\hline & \multicolumn{5}{|c|}{ Colmo basal } \\
\hline 90 & $0,580 \mathrm{ab}$ & $0,546 \mathrm{ab}$ & $0,693 a$ & $0,464 b$ & $0,571 \mathrm{~A}$ \\
\hline 180 & $0,201 \mathrm{a}$ & $0,234 \mathrm{a}$ & $0,209 a$ & $0,245 a$ & $0,222 \mathrm{BC}$ \\
\hline 360 & $0,253 a$ & $0,257 \mathrm{a}$ & $0,276 \mathrm{a}$ & $0,318 \mathrm{a}$ & $0,276 \mathrm{~B}$ \\
\hline 540 & $0,233 a$ & $0,218 \mathrm{a}$ & $0,176 \mathrm{a}$ & $0,213 \mathrm{a}$ & $0,210 \mathrm{C}$ \\
\hline Média & $0,316 \mathrm{a}$ & $0,313 \mathrm{a}$ & $0,338 \mathrm{a}$ & $0,310 \mathrm{a}$ & \\
\hline \multirow[t]{2}{*}{$\mathrm{CV}$} & 26,86 & & & & \\
\hline & \multicolumn{5}{|c|}{ Colmo intermediário } \\
\hline 90 & $0,852 \mathrm{a}$ & $0,665 b$ & - & - & - \\
\hline 180 & $0,231 \mathrm{ab}$ & $0,211 b$ & $0,250 \mathrm{a}$ & $0,256 \mathrm{a}$ & $0,237 \mathrm{C}$ \\
\hline 360 & $0,256 \mathrm{a}$ & $0,255 \mathrm{a}$ & $0,250 \mathrm{a}$ & $0,263 \mathrm{a}$ & $0,256 \mathrm{BC}$ \\
\hline 540 & $0,256 \mathrm{bc}$ & $0,164 \mathrm{c}$ & $0,307 \mathrm{ab}$ & $0,327 \mathrm{a}$ & $0,263 \mathrm{~A}$ \\
\hline \multirow[t]{2}{*}{ Média } & $0,398 \mathrm{a}$ & $0,323 b$ & $0,263 \mathrm{c}$ & $0,282 \mathrm{c}$ & \\
\hline & \multicolumn{5}{|c|}{ Colmo apical } \\
\hline 90 & $1,634 \mathrm{~b}$ & $1,908 \mathrm{a}$ & - & - & - \\
\hline 180 & $0,399 \mathrm{c}$ & $0,440 \mathrm{bc}$ & $0,756 \mathrm{a}$ & $0,597 \mathrm{ab}$ & $0,548 \mathrm{C}$ \\
\hline 360 & $0,725 \mathrm{ab}$ & $0,562 b$ & $0,558 \mathrm{~b}$ & $0,831 \mathrm{a}$ & $0,669 \mathrm{~A}$ \\
\hline 540 & $0,847 \mathrm{a}$ & $0,466 \mathrm{c}$ & $0,670 \mathrm{ab}$ & $0,545 \mathrm{bc}$ & $0,632 \mathrm{AB}$ \\
\hline \multirow[t]{2}{*}{ Média } & $0,901 \mathrm{a}$ & $0,844 \mathrm{a}$ & $0,661 \mathrm{~b}$ & $0,657 \mathrm{~b}$ & \\
\hline & \multicolumn{5}{|c|}{ Folhas } \\
\hline 90 & $2,005 \mathrm{a}$ & $1,968 \mathrm{a}$ & $2,028 \mathrm{a}$ & $1,377 b$ & $1,845 \mathrm{~A}$ \\
\hline 180 & $1,850 \mathrm{a}$ & $1,797 b$ & $1,900 \mathrm{a}$ & $1,317 \mathrm{c}$ & $1,716 \mathrm{AB}$ \\
\hline 360 & $1,626 a$ & $1,315 b$ & $1,776 \mathrm{a}$ & $1,454 b$ & $1,542 \mathrm{~B}$ \\
\hline 540 & $1,749 \mathrm{a}$ & $1,514 \mathrm{ab}$ & $1,700 \mathrm{a}$ & $1,377 \mathrm{~b}$ & $1,585 \mathrm{~B}$ \\
\hline Média & $1,807 \mathrm{ab}$ & $1,648 b$ & $1,851 \mathrm{a}$ & $1,381 \mathrm{c}$ & \\
\hline
\end{tabular}

(1)Médias seguidas de mesma letra, minúscula nas linhas e maiúscula nas colunas, não diferem entre si pelo teste de Tukey a 5\% de probabilidade; médias de 4 repetições; os coeficientes de variação relativos aos dados das raízes, colmo basal, colmo intermediário, colmo apical e folhas foram $12,40 \%$, 26,86\%, 14,63\%, 15,46\% e 10,65\%, respectivamente. 
Nos colmos, a concentração aumentou da base para o ápice, já que o elemento está associado às áreas de maior crescimento. Comparando-se os híbridos nas condições de estresse de nitrogênio, a variedade SP70-1143 tendeu a acumular uma maior quantidade de $\mathrm{N}$, tanto nos colmos como nas folhas, em relação à SP79-2312, que é uma variedade selecionada para solos mais ricos. Entre as espécies, Krakatau acumulou mais $\mathrm{N}$ nas folhas e colmo basal do que a Chunnee. Reis Júnior et al. (2000a) ao trabalhar com as variedades SP70-1143 e SP79-2312, verificaram dois picos nos valores de conteúdo de nitrogênio ( $\mathrm{N}$ total), tendo o primeiro e mais elevado ocorrido aos 90 DAP, e o outro aos 360 DAP, independentemente do cultivo, com ou sem adubação nitrogenada. Esses autores também encontraram valores de $\mathrm{N}$ total mais elevados nas raízes, dos 90 aos 450 DAP, quando comparados aos colmos. Outros autores citam, também, que a concentração de nitrogênio decresce com a idade (Rossiello, 1987; Thangavelu
\& Rao, 1996). Destaca-se que essas foram as variedades que obtiveram maiores contribuições via FBN, na quantificação efetuada por Urquiaga et al. (1992), só tendo perdido para a variedade CB 45-3 (74\% do N derivado da FBN).

De forma geral, o nitrato tendeu a se acumular nas raízes, no final do ciclo da cultura, principalmente nas espécies Krakatau e Chunnee (Tabela 2). Nos colmos, essa fração estava concentrada naqueles mais velhos, tendo atingido aproximadamente 3,5 e $4 \mathrm{mmol} \mathrm{g}^{-1}$ de matéria fresca nas variedades SP70-1143 e SP79-2312; a variedade Krakatau acumulou em torno de metade da concentração das outras, e o pico de acúmulo ocorreu aos 360 DAP (colmo apical). Silveira \& Crocomo (1989), em amostras do colmo da variedade NA 56-79, cultivada em solução nutritiva com níveis combinados de $\mathrm{N}$ e $\mathrm{K}$, aos 180 DAP, obtiveram valores de 0,19, 14,73 e $8,55 \mu \mathrm{mol} \mathrm{g}{ }^{-1}$ de matéria seca, para os diversos tratamentos aplicados. Essa fração não se acumulou nas

Tabela 2. Concentração de nitrato ( $\mu \mathrm{mol} \mathrm{g}{ }^{-1}$ de matéria fresca), em diferentes partes da planta de cana-de-açúcar (Saccharum spp.), em função de dias após plantio (DAP) ${ }^{(1)}$.

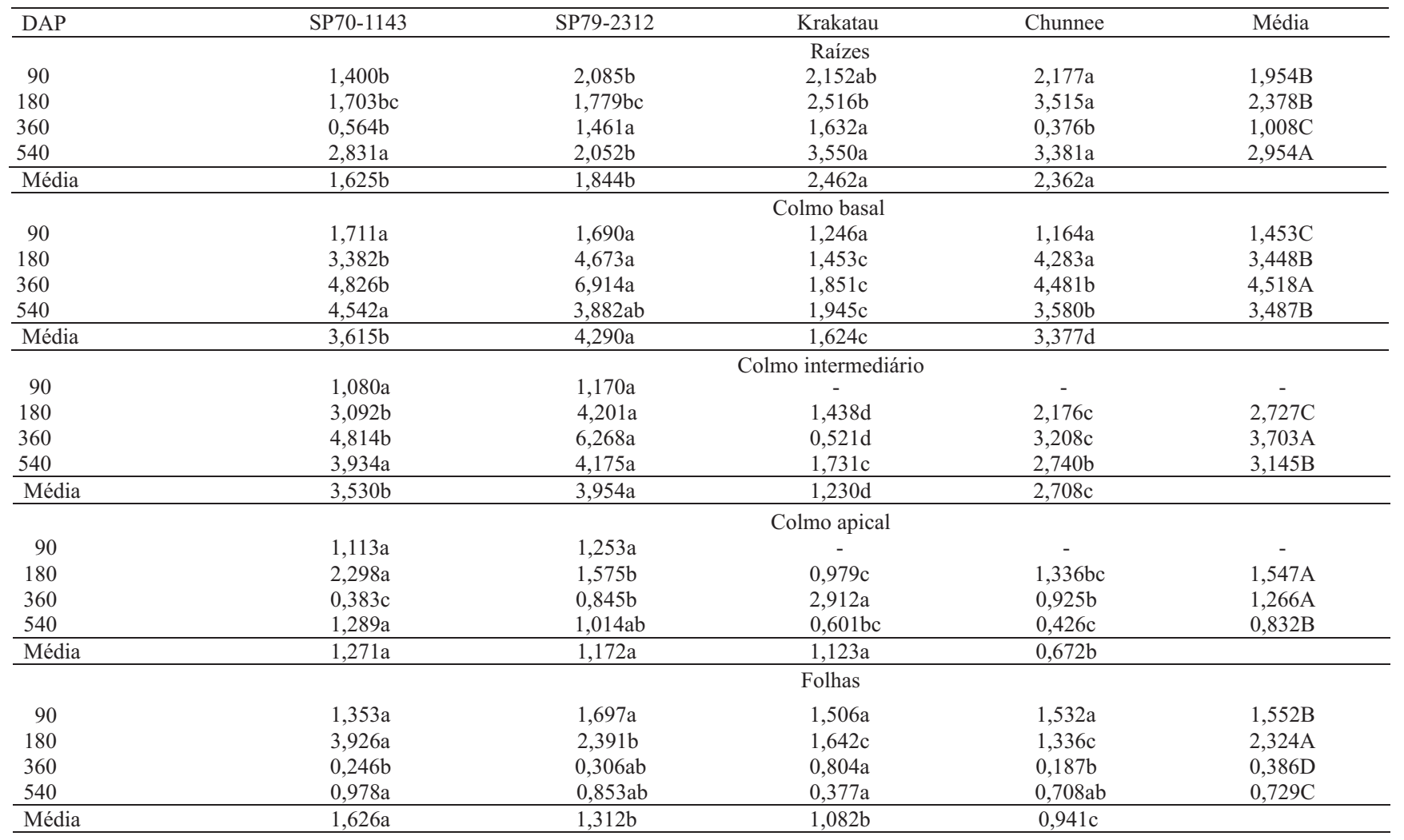

(1)Médias seguidas de mesma letra, minúscula nas linhas e maiúscula nas colunas, não diferem entre si pelo teste de Tukey a 5\% de probabilidade; média de 4 repetições; os coeficientes de variação relativos aos dados das raízes, colmo basal, colmo intermediário, colmo apical e folhas foram $19,14 \%$, 13,98\%, 14,16\%, 15,37\% e 22,19\%, respectivamente. 
folhas, teve como pico de acumulação a fase vegetativa (90 DAP) e foi maior na variedade SP70-1143.

De modo geral, a concentração de $\mathrm{N}$ amino nas raízes apresentou uma variação sazonal e varietal maior do que as frações anteriores (Tabela 3). A variedade SP79-2312 acumulou o maior teor dessa fração nas raízes, aos 90 e 540 DAP. A acumulação nos colmos acompanhou a variação sazonal das raízes, entretanto a variação varietal não seguiu nenhum padrão. A fração de colmos que mais acumulou $\mathrm{N}$ amino foi o colmo apical, especialmente na espécie Saccharum barberi (Chunnee), chegando a acumular três vezes mais do que a variedade SP70-1143 no mesmo período. As folhas acumularam mais $\mathrm{N}$ amino aos 90 DAP, e as quatro variedades decresceram cerca de $1 / 3$ do valor inicial, ao final do ciclo.

A maior população de $G$. diazotrophicus estava presente nas raízes, principalmente no início do ciclo. Esse fato está relacionado com o efeito de diluição. Entretanto como as raízes de gramíneas são profusas, embora o número diminua por unidade de massa (g de matéria fresca), a população pode ser maior pela matéria fresca total, que aumenta com a idade. As variedades comerciais (SP70-1143 e SP79-2312) apresentaram uma população dez vezes maior de G. diazotrophicus aos 90 DAP, diferindo de Krakatau e Chunnee, e apenas a variedade SP70-1143 manteve a população mais alta até os 180 DAP (Tabela 4). O fato de ter existido uma maior população de $G$. diazotrophicus, na variedade SP70-1143, sugere que há maior potencial dessa variedade, com relação à fixação biológica de nitrogênio, como já citado por Urquiaga et al. (1992), que obtiveram $67 \%$ do nitrogênio utilizado em seu ciclo, da FBN. As maiores populações de bactérias diazotróficas, encontradas nas raízes, estão de acordo com os estudos realizados em cana-de-açúcar por Reis Júnior et al. (2000a, 2000b).

De modo geral, a população nos colmos e folhas foi inferior a $10^{4}$ células por g de matéria fresca, não tendo

Tabela 3. Concentração de N amino livre ( $\mu \mathrm{mol} \mathrm{g}{ }^{-1}$ de matéria fresca), em diferentes partes da planta de cana-de-açúcar (Saccharum spp.), em função de dias após plantio (DAP) ${ }^{(1)}$.

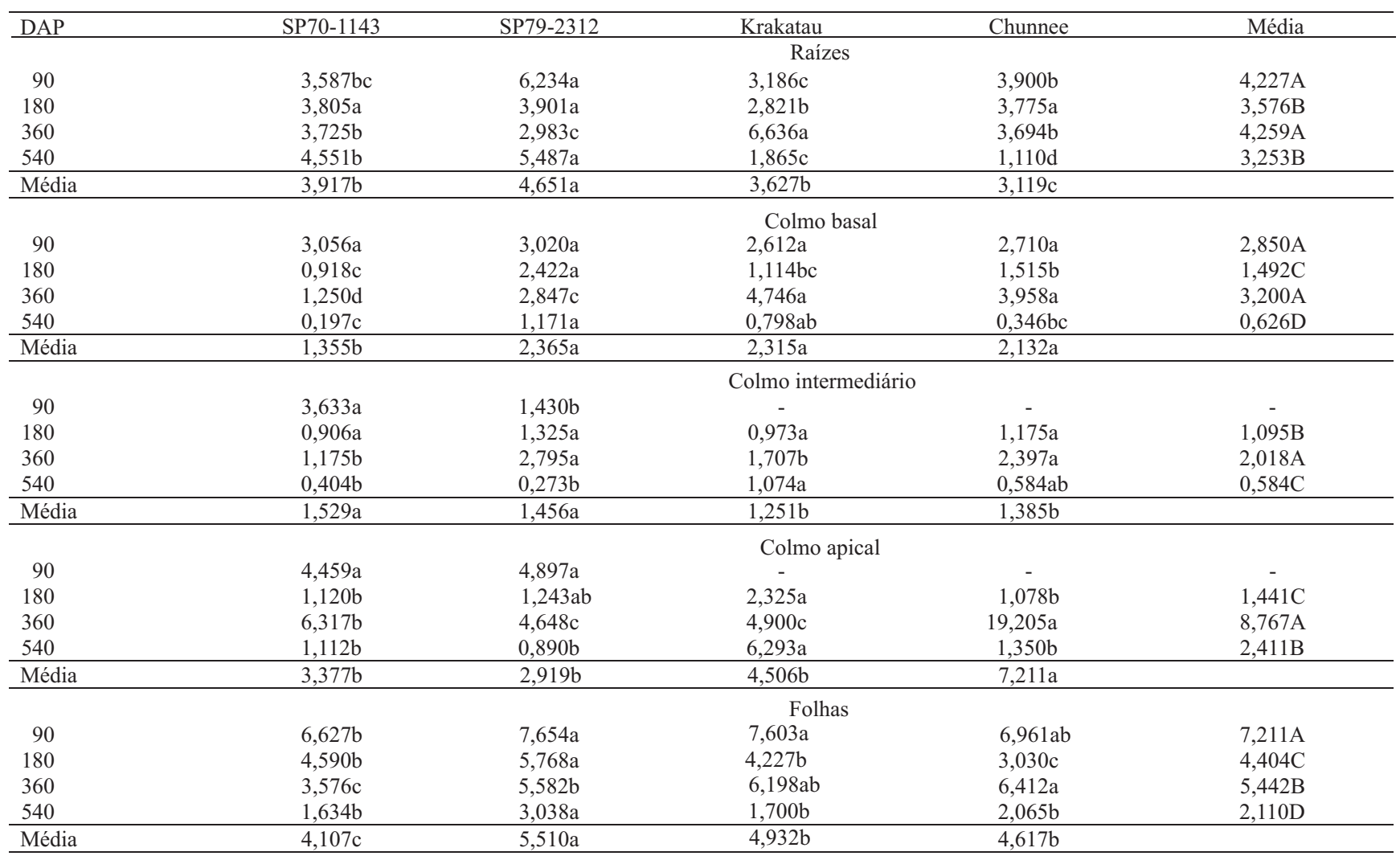

(1)Médias seguidas de mesma letra, minúscula nas linhas e maiúscula nas colunas, não diferem entre si pelo teste de Tukey a 5\% de probabilidade; médias de 4 repetições; os coeficientes de variação relativos aos dados das raízes, colmo basal, colmo intermediário, colmo apical e folhas foram $8,86 \%, 12,94 \%$, 26,57\%, $15,37 \%$ e $8,74 \%$, respectivamente. 
diferido entre variedades ou épocas de coleta. Baixos números populacionais também foram observados por Gonzales \& Barraquio (2000), nas Filipinas, pelo método aqui utilizado, o NMP. Tal fato pode ser atribuído ao estado fenológico da planta, como sugerido por Reis Júnior et al. (2000a). A população de G. diazotrophicus decresceu com a aproximação do final do ciclo da cultura da cana (Reis Júnior et al., 2000b). Asis et al. (2000) obtiveram números em torno de $4,5 \times 10^{5}$ células por g de matéria fresca de colmos de cana-de-açúcar plantada no Japão. Estes autores isolaram 21 estirpes fixadoras de nitrogênio, tendo utilizado o mesmo meio de cultivo deste trabalho, para o isolamento de G. diazotrophicus. Muñoz-Rojas \& CaballeroMellado (2003) observaram que a população das estirpes de G. diazotrophicus, inoculada em plantas micropropagadas de diferentes variedades de canade-açúcar, diminuiu drasticamente, em relação à ida- de da planta, e que tal decréscimo ocorreu independentemente do nível de fertilização, genótipo da bactéria ou variedade da planta.

Com relação à população de Herbaspirillum spp. nas raízes, observou-se pouca variação no número populacional ao longo do tempo $\left(10^{2}\right.$ a $10^{4}$ células por $g$ de matéria fresca), e os números foram superiores aos observados para G. diazotrophicus (Tabela 5). Embora não tenha sido observada diferença varietal, a população se manteve em números maiores por mais tempo, independentemente da época de amostragem. Essa tendência também foi verificada por Reis Júnior et al. (2000a, 2000b). Herbaspirillum spp. figura entre a população microbiana do solo, e pode tanto obter metabólitos de carbono na rizosfera, quanto no interior das raízes, hipótese reforçada por observações de Muthukumarasamy et al. (1999), que não verificaram diferenças na população desse gênero, na rizosfera e no interior das raízes.

Tabela 4. População de Gluconacetobacter diazotrophicus (log do número de células g-1 de matéria fresca), em diferentes partes da planta de cana-de-açúcar (Saccharum spp.), em função e dias após plantio (DAP)(1).

\begin{tabular}{|c|c|c|c|c|c|}
\hline DAP & SP70-1143 & SP79-2312 & Krakatau & Chunnee & Média \\
\hline & \multicolumn{5}{|c|}{ Raízes } \\
\hline 90 & $4,220 \mathrm{a}$ & $4,775 \mathrm{a}$ & $2,957 \mathrm{~b}$ & $2,477 b$ & $3,607 \mathrm{~A}$ \\
\hline 180 & $3,811 \mathrm{a}$ & $2,569 \mathrm{~b}$ & $2,652 \mathrm{ab}$ & $2,477 b$ & $2,877 \mathrm{AB}$ \\
\hline 360 & $2,957 \mathrm{a}$ & $2,477 \mathrm{a}$ & $2,508 \mathrm{a}$ & $2,477 \mathrm{a}$ & $2,605 \mathrm{~B}$ \\
\hline 540 & $2,957 \mathrm{a}$ & $2,707 \mathrm{a}$ & $2,477 \mathrm{a}$ & $2,477 \mathrm{a}$ & $2,655 \mathrm{C}$ \\
\hline \multirow[t]{2}{*}{ Média } & $3,486 a$ & $3,132 \mathrm{ab}$ & $2,649 \mathrm{bc}$ & $2,477 \mathrm{c}$ & \\
\hline & \multicolumn{5}{|c|}{ Colmo basal } \\
\hline 90 & $2,477 \mathrm{a}$ & $2,477 \mathrm{a}$ & $2,477 \mathrm{a}$ & $2,477 \mathrm{a}$ & $2,477 \mathrm{~A}$ \\
\hline 180 & $2,727 b$ & $2,477 b$ & $2,802 b$ & $4,105 \mathrm{a}$ & $2,903 \mathrm{~A}$ \\
\hline 360 & $3,187 \mathrm{a}$ & $3,251 \mathrm{a}$ & $2,852 \mathrm{a}$ & $2,477 \mathrm{a}$ & $2,942 \mathrm{~A}$ \\
\hline 540 & $2,477 \mathrm{a}$ & $2,477 \mathrm{a}$ & $2,477 \mathrm{a}$ & $2,477 \mathrm{a}$ & $2,477 \mathrm{~A}$ \\
\hline \multirow[t]{2}{*}{ Média } & $2,717 \mathrm{a}$ & $2,671 \mathrm{a}$ & $2,527 \mathrm{a}$ & $2,884 a$ & \\
\hline & \multicolumn{5}{|c|}{ Colmo intermediário } \\
\hline 90 & $2,477 \mathrm{a}$ & $2,477 \mathrm{a}$ & - & - & - \\
\hline 180 & $2,771 \mathrm{a}$ & $2,508 \mathrm{a}$ & $2,652 \mathrm{a}$ & $2,477 \mathrm{a}$ & $2,602 \mathrm{~A}$ \\
\hline 360 & $3,021 \mathrm{a}$ & $2,477 \mathrm{a}$ & $2,890 \mathrm{a}$ & $2,477 \mathrm{a}$ & $2,716 \mathrm{~A}$ \\
\hline 540 & $2,477 \mathrm{a}$ & $2,477 \mathrm{a}$ & $3,152 \mathrm{a}$ & $2,477 \mathrm{a}$ & $2,646 \mathrm{~A}$ \\
\hline \multirow[t]{2}{*}{ Média } & $2,686 a$ & $2,485 a$ & $2,898 \mathrm{a}$ & $2,477 \mathrm{a}$ & \\
\hline & \multicolumn{5}{|c|}{ Colmo apical } \\
\hline 90 & $2,508 \mathrm{a}$ & $2,477 \mathrm{a}$ & - & - & - \\
\hline 180 & $2,596 \mathrm{a}$ & $2,477 \mathrm{a}$ & $2,477 \mathrm{a}$ & $2,477 \mathrm{a}$ & $2,507 \mathrm{~A}$ \\
\hline 360 & $3,021 \mathrm{a}$ & $2,508 \mathrm{ab}$ & $2,508 \mathrm{ab}$ & $2,477 \mathrm{a}$ & $2,659 \mathrm{~A}$ \\
\hline 540 & $2,477 \mathrm{a}$ & $2,477 \mathrm{a}$ & $2,477 \mathrm{a}$ & $2,477 \mathrm{a}$ & $2,477 \mathrm{~A}$ \\
\hline \multirow[t]{2}{*}{ Média } & $2,651 \mathrm{a}$ & $2,507 \mathrm{a}$ & $2,484 a$ & $2,477 \mathrm{a}$ & \\
\hline & \multicolumn{5}{|c|}{ Folhas } \\
\hline 90 & $2,802 \mathrm{a}$ & $2,477 \mathrm{a}$ & $2,477 a$ & $2,477 \mathrm{a}$ & $2,558 \mathrm{~A}$ \\
\hline 180 & $2,477 \mathrm{a}$ & $2,477 \mathrm{a}$ & $2,477 \mathrm{a}$ & $2,477 \mathrm{a}$ & $2,477 \mathrm{~A}$ \\
\hline 360 & $2,477 b$ & $3,187 \mathrm{a}$ & $2,477 b$ & $2,477 b$ & $2,655 \mathrm{~A}$ \\
\hline 540 & $2,477 \mathrm{a}$ & $2,477 \mathrm{a}$ & $2,477 \mathrm{a}$ & $2,477 \mathrm{a}$ & $2,477 \mathrm{~A}$ \\
\hline Média & $2,558 \mathrm{a}$ & $2,654 a$ & $2,477 \mathrm{a}$ & $2,477 \mathrm{a}$ & \\
\hline
\end{tabular}

${ }^{(1)}$ Médias seguidas de mesma letra, minúscula nas linhas e maiúscula nas colunas, não diferem entre si pelo teste de Tukey a 5\% de probabilidade; médias de 4 repetições; os coeficientes de variação relativos aos dados das raízes, colmo basal, colmo intermediário, colmo apical e folhas, foram $21,60 \%, 21,00 \%, 28,83 \%, 12,48 \%$ e 10,62 , respectivamente. 
Vale ressaltar que os toletes usados para a propagação da cana-de-açúcar carregam uma população nativa de bactérias diazotróficas, pertencentes aos gêneros avaliados neste trabalho, e outros como Azospirillum, Burkholderia etc. Mesmo que tais populações estabelecidas se multipliquem e colonizem as raízes da cana-de-açúcar, os números populacionais estão de acordo com os dados descritos para essa e outras gramíneas, onde as raízes apresentam os maiores valores (Olivares, 1997).

Nos colmos e folhas, a população manteve-se em números relativamente baixos ao longo do ciclo, independentemente da variedade e época de coleta. Em algumas coletas, esse número elevou-se em torno de dez vezes (Tabela 5). Muthukumarasamy et al. (1999) verificaram que a população de Herbaspirillum spp. foi mais abundante em colmos e folhas, que nas raízes e rizosfera. Entretanto, Reis Júnior et al. (2000b) observaram tendência inversa, e também verificaram que a população dessa bactéria não sofreu decréscimo com a aproximação do final do ciclo, nas duas variedades avaliadas (SP70-1143 e SP79-2312), nem tampouco ao longo do ciclo das canas não comerciais (Chunnee e Krakatau). Olivares (1997) verificou decréscimo nos números de Herbaspirillum spp., em plântulas de cana-de-açúcar que passaram por inoculação, com o aumento da idade, sob condições de casa de vegetação.

A composição do $\mathrm{N}$, nas variedades estudadas, apresentou-se dentro dos níveis esperados para gramíneas e, principalmente, para a cana de açúcar, que produz sacarose e não acumula nitrogênio em quantidades elevadas em nenhum de seus órgãos. As diferenças observadas estão relacionadas com as características genotípicas, pois trata-se de duas espécies diferentes e dois Saccharum híbridos. Não foi verificada correlação entre as formas de nitrogênio estudadas e a população de bactérias. A população

Tabela 5. População de Herbaspirillum spp. (log do número de células g-1 de matéria fresca), em diferentes partes da planta de cana de açúcar (Saccharum spp.), em função de dias após plantio (DAP) ${ }^{(1)}$.

\begin{tabular}{|c|c|c|c|c|c|}
\hline DAP & SP70-1143 & SP79-2312 & Krakatau & Chunnee & Média \\
\hline & \multicolumn{5}{|c|}{ Raízes } \\
\hline 90 & $4,872 \mathrm{a}$ & $5,023 \mathrm{a}$ & $4,212 \mathrm{a}$ & $3,624 \mathrm{a}$ & $4,433 \mathrm{~A}$ \\
\hline 180 & $3,989 \mathrm{a}$ & $4,261 \mathrm{a}$ & $4,936 \mathrm{a}$ & $3,688 \mathrm{a}$ & $4,219 \mathrm{~A}$ \\
\hline 360 & $4,265 \mathrm{a}$ & $3,251 \mathrm{a}$ & $3,865 \mathrm{a}$ & $3,187 \mathrm{a}$ & $3,642 \mathrm{~A}$ \\
\hline 540 & $3,758 \mathrm{a}$ & $2,957 \mathrm{a}$ & $2,724 a$ & $2,477 \mathrm{a}$ & $2,979 \mathrm{~A}$ \\
\hline \multirow[t]{2}{*}{ Média } & $4,221 \mathrm{a}$ & $3,873 \mathrm{ab}$ & $3,934 \mathrm{ab}$ & $3,244 \mathrm{~b}$ & \\
\hline & \multicolumn{5}{|c|}{ Colmo basal } \\
\hline 90 & $2,508 \mathrm{a}$ & $2,477 \mathrm{a}$ & $2,477 \mathrm{a}$ & $2,802 \mathrm{a}$ & $2,566 \mathrm{~A}$ \\
\hline 180 & $2,508 \mathrm{a}$ & $2,477 \mathrm{a}$ & $2,477 \mathrm{a}$ & $2,477 \mathrm{a}$ & $2,485 \mathrm{~A}$ \\
\hline 360 & $2,477 \mathrm{a}$ & $2,477 \mathrm{a}$ & $2,625 a$ & $2,477 \mathrm{a}$ & $2,521 \mathrm{~A}$ \\
\hline 540 & $2,596 a$ & $2,477 \mathrm{a}$ & $2,477 \mathrm{a}$ & $2,477 \mathrm{a}$ & $2,507 \mathrm{~A}$ \\
\hline \multirow[t]{2}{*}{ Média } & $2,522 \mathrm{a}$ & $2,477 \mathrm{a}$ & $2,521 \mathrm{a}$ & $2,558 \mathrm{a}$ & \\
\hline & \multicolumn{5}{|c|}{ Colmo intermediário } \\
\hline 90 & $2,477 \mathrm{a}$ & $2,477 \mathrm{a}$ & - & - & - \\
\hline 180 & $2,477 \mathrm{a}$ & $2,477 \mathrm{a}$ & $2,477 \mathrm{a}$ & $2,477 \mathrm{a}$ & $2,477 \mathrm{~A}$ \\
\hline 360 & $2,477 b$ & $2,477 b$ & $3,219 \mathrm{a}$ & $2,477 b$ & $2,662 \mathrm{~A}$ \\
\hline 540 & $3,227 \mathrm{a}$ & $2,508 \mathrm{~b}$ & $2,569 \mathrm{~b}$ & $2,477 \mathrm{~b}$ & $2,695 \mathrm{~A}$ \\
\hline \multirow[t]{2}{*}{ Média } & $2,665 \mathrm{a}$ & $2,485 a$ & $2,755 \mathrm{a}$ & $2,477 \mathrm{a}$ & \\
\hline & \multicolumn{5}{|c|}{ Colmo apical } \\
\hline 90 & $2,477 \mathrm{a}$ & $2,477 \mathrm{a}$ & - & - & - \\
\hline 180 & $2,500 \mathrm{a}$ & $2,477 \mathrm{a}$ & $2,477 \mathrm{a}$ & $2,477 \mathrm{a}$ & $2,485 \mathrm{~A}$ \\
\hline 360 & $2,477 \mathrm{a}$ & $2,477 \mathrm{a}$ & $2,477 \mathrm{a}$ & $2,477 \mathrm{a}$ & $2,477 \mathrm{~A}$ \\
\hline 540 & $2,707 \mathrm{a}$ & $2,477 \mathrm{a}$ & $2,477 \mathrm{a}$ & $2,477 \mathrm{a}$ & $2,535 \mathrm{~A}$ \\
\hline \multirow[t]{2}{*}{ Média } & $2,542 \mathrm{a}$ & $2,477 \mathrm{a}$ & $2,477 \mathrm{a}$ & $2,477 \mathrm{a}$ & \\
\hline & \multicolumn{5}{|c|}{ Folhas } \\
\hline 90 & $2,652 a$ & $2,477 \mathrm{a}$ & $2,477 \mathrm{a}$ & $2,508 \mathrm{a}$ & $2,529 \mathrm{~A}$ \\
\hline 180 & $2,539 a$ & $2,627 \mathrm{a}$ & $2,477 \mathrm{a}$ & $2,477 \mathrm{a}$ & $2,530 \mathrm{~A}$ \\
\hline 360 & $2,477 \mathrm{a}$ & $2,477 \mathrm{a}$ & $2,477 \mathrm{a}$ & $2,477 b$ & $2,477 \mathrm{~A}$ \\
\hline 540 & $2,477 \mathrm{~b}$ & $2,477 \mathrm{~b}$ & $3,057 \mathrm{a}$ & $2,477 b$ & $2,622 \mathrm{~A}$ \\
\hline Média & $2,536 \mathrm{a}$ & $2,530 \mathrm{a}$ & $2,622 a$ & $2,485 \mathrm{a}$ & \\
\hline
\end{tabular}

(1)Médias seguidas de mesma letra, minúscula nas linhas e maiúscula nas colunas, não diferem entre si pelo teste de Tukey a 5\% de probabilidade; média de 4 repetições; os coeficientes de variação relativos aos dados das raízes, colmo basal, colmo intermediário, colmo apical e folhas foram $22,14 \%, 7,16 \%, 14,01 \%, 5,32 \%$ e $7,16 \%$, respectivamente. 
das duas espécies apresentou números baixos, em todos os materiais vegetais estudados, e maiores esforços devem ser direcionados na busca de metodologias que quantifiquem a população total de bactérias fixadoras.

\section{Conclusões}

1. Os valores do porcentual de nitrogênio tendem a ser mais elevados aos 90 dias após o plantio nos colmos e nas folhas.

2. As maiores concentrações de $\mathrm{N}$ amino ocorrem nas raízes, colmo basal e folhas da variedade SP79-2312 e no colmo apical do genótipo Chunnee.

3. Os maiores valores na concentração de nitrato são observados no colmo basal e intermediário das variedades SP79-2312, SP70-1143, e no colmo basal da Chunnee.

4. As maiores populações de Gluconacetobacter diazotrophicus são observadas nas raízes das variedades SP70-1143 e SP79-2312.

5. As populações de Herbaspirillum spp. são maiores nas raízes de todos os genótipos.

6. As análises das formas de nitrogênio não se correlacionam à população de bactérias diazotróficas avaliadas.

\section{Agradecimentos}

Ao CNPq, pelas bolsas de produtividade concedidas aos pesquisadores; ao Pronex II/CNPq, pelo apoio financeiro.

\section{Referências}

ASIS, C.A.; KUBOTA, M.; OHTA, H.; ARIMA, Y.; CHEBOTAR, V.K.; TSUCHIY, A.K.; AKAO, S. Isolation and partial characterization of endophytic diazotrophs associated with japanese sugarcane cultivar. Soil Science and Plant Nutrition, v.46, p.759765, 2000

AZEREDO, D.F.; BOLSANELLO, J.; WEBER, H.; VIEIRA, J.R. Nitrogênio na cana planta: doses e fracionamento. Revista STAB, v.4, p.32-36, 1986.

BALDANI, J.I.; BALDANI, V.L.D.; SELDIN, L.; DÖBEREINER, J. Characterization of Herbaspirillum seropedicae gen. nov., sp. nov., a root associated nitrogen-fixing. International Journal of Systematic Bacteriology, v.36, p.86-93, 1986.

BALDANI, J.I.; POT, B.; KIRCHHOF, G.; FALSEN, E.; BALDANI, V.L.D.; OLIVARES, F.L.; HORSTE, B.; KERSTERE, K.; HARTMANN, A.; GILLIS, M.; DÖBEREINER, J. Inclusion of
"Pseudomonas" rubrisubalbicans, a mild plant pathogen within the genus Herbaspirillum. International Journal of Systematic Bacteriology, v.46, p.802-810, 1996.

BASTIÁN, F.; COHEN, A.; PICCOLI, P.; LUNA, V.; BARALDI, R.; BOTTINI, R. Production of indole-3-acetic acid and gibberellins $\mathrm{A}_{1}$ and $\mathrm{A}_{3}$ by Acetobacter diazotrophicus and Herbaspirillum seropedicae in chemically-defined culture media. Plant Growth Regulation, v.24, p.7-11, 1998.

CATALDO, D.A.; SCHARADER, L.E.; YONGS, L.R. Analyses by colorimetric assay of total nitrogen in plant tissues high in nitrate. Crop Science, v.14, p.854-856, 1975.

CAVALCANTE, V.A.; DÖBEREINER, J. A new acid-tolerant nitrogen-fixing bacterium associated with sugarcane. Plant and Soil, v.108, p.23-31, 1988.

CLEMENTS, H.F. Sugarcane crop logging and control: principles and practices. [London]: Pitman Publishing; [Honolulu]: The University Press of Hawaii, 1980. 520p.

DÖBEREINER, J.; BALDANI, V.L.D.; BALDANI, J.I. Como isolar e identificar bactérias diazotróficas em plantas não leguminosas. Brasília: Embrapa-SPI; Itaguaí-RJ: Embrapa-CNPAB, 1995. 60p.

FERNANDES, M.S.; ROSSIELLO, R.O.P. Mineral nitrogen in plant physiology and plant nutrition. Critical Reviews in Plant Sciences, v.14, p.111-148, 1995.

FUENTES-RAMÍREZ, L.E.; JIMÉNEZ-SALGADO, T.; ABARCA-OCAMPO, I.R.; CABALLERO-MELLADO, J. Acetobacter diazotrophicus, an indole-acetic acid producing bacterium isolated from sugar cane cultivars in México. Plant and Soil, v.154, p.145-150, 1993.

GONZALEZ, M.S.; BARRAQUIO, W.L. Isolation and characterization of Acetobacter diazotrophicus (Gillis) in Saccharum officinarum L., S. spontaneum L., and Erianthus sp. Philippine Agricultural Scientist, v.83, p.173-181, 2000.

JAMES, E.K. Nitrogen fixation in endophytic and associative symbiosis. Field Crops Research, v.65, p.197-209, 2000.

MICHIGAN STATE UNIVERSITY. MSTAT-C: a software program for the design, management, and analysis of agronomic research experiments. East Lansing: 1989. 1 CD-ROM.

MUÑOZ-ROJAS, J.; CABALLERO-MELLADO, J. Population dynamics of Gluconacetobacter diazotrophicus in sugarcane cultivars and its effect on plant growth. Microbial Ecology, v.46, p.454-464, 2003.

MUTHUKUMARASAMY, R.; REVATHI, G.; LAKSHMINARASIMHAN, C. Influence of $\mathrm{N}$ fertilisation on the isolation of Acetobacter diazotrophicus and Herbaspirillum spp. from indian sugarcane varieties. Biology and Fertility of Soils, v.29, p.157-164, 1999.

OLIVARES, F.L. Taxonomia, ecologia e mecanismos envolvidos na infecção e colonização de cana-de-açúcar (Saccharum sp. híbrido) por bactérias diazotróficas endofíticas do gênero Herbaspirillum. 1997. 328p. Tese (Doutorado) - Universidade Federal Rural do Rio de Janeiro, Seropédica.

REIS JUNIOR, F.B. dos; REIS, V.M.; URQUIAGA, S.; DÖBEREINER, J. Influence of nitrogen fertilisation on the population 
of diazotrophic bacteria Herbaspirillum spp. and Acetobacter diazotrophicus in sugar cane (Saccharum spp.). Plant and Soil, v.219, p.153-159, 2000a.

REIS JUNIOR, F.B. dos; REIS, V.M.; URQUIAGA, S.; DÖBEREINER, J. Ocorrência de bactérias diazotróficas em diferentes genótipos de cana-de-açúcar. Pesquisa Agropecuária Brasileira, v.35, p.985-994, 2000b.

ROSSIELLO, R.O.P. Bases fisiológicas da acumulação de nitrogênio e potássio em cana-de-açúcar (Saccharum spp., cv. NA 56-79) em resposta à adubação nitrogenada em Cambissolo. 172p. 1987. Tese (Doutorado) - Escola Superior de Agricultura Luiz de Queiroz, Piracicaba.

SILVEIRA, J.A.G. Interações entre assimilação de nitrogênio e o crescimento de cana-de-açúcar (Saccharum spp.) cultivada em condições de campo. 1985. 152p. Tese (Doutorado) - Escola Superior de Agricultura Luiz de Queiroz, Piracicaba.

SILVEIRA, J.A.G.; CROCOMO, O.J. Sintomas de deficiência de potássio induzidos pelo acúmulo de aminoácidos e amônia em cana- de-açúcar. Revista Brasileira de Ciência do Solo, v.13, p.329334, 1989.

TEDESCO, M.J. Extração simultânea de N, P, K, Ca e Mg em tecidos de plantas por digestão com $\mathrm{H}_{2} \mathrm{SO}_{4}$. Porto Alegre: UFRGS, 1983. 23p.

THANGAVELU, S.; RAO, K.C. Total nitrogen content present in immature, mature and over-mature cane juice of some sugarcane genetic stocks. Indian Sugar, v.46, p.507-511, 1996.

URQUIAGA, S.; CRUZ, K.H.S.; BODDEY, R.M. Contribution of nitrogen-fixation to sugarcane: nitrogen-15 and nitrogen balance estimate. Soil Science Society of America Journal, v.56, p.105-114, 1992.

YEEM, E.W.; COCKING, E.C. The determination of aminoacid with ninhydrin. Analyst, v.80, p.209-213, 1955.

YONEYAMA, T.; MURAOKA, T.; KIM, T.H.; DACANAY, E.V.; NAKANISHI, Y. The natural ${ }^{15} \mathrm{~N}$ abundance of sugarcane and neighbouring plants in Brazil, the Philippines and Miyako (Japan). Plant and Soil, v.189, p.239-244, 1997.

Recebido em 3 de fevereiro de 2005 e aprovado em 5 de abril de 2005 